Egyptian

Orthodontic Journal

\title{
COMPARISON BETWEEN THE EFFECT OF AIR-ABRASION BEFORE AND AFTER CONVENTIONAL ACID ETCHING ON THE SHEAR BOND STRENGTH IBRAHIM MAZEN NEGM ${ }^{1}$, KHALED SAMIR ABOULAZM ${ }^{2}$ ABSTRACT:
}

Introduction: Recently, air-abrasion technology has been examined for potential applications within the field of orthodontics as an alternate method of enamel surface treatment especially with the introduction of intraoral sand 6lasters. Therefore, the aim of this study was to compare the effect of sandblasting of enamel before and after conventional acid-etch bond technique on the shear 6ond strength. Methods: the study consisted of sixty freshly extracted human premolars that were equally and randomly divided into two groups ( $A$ and $B$ ). In group $A$ the enamel surface treatment involved sandblasting followed by acid etching, while in group $B$ enamel surface treatment involved acid etching followed by sand6lasting. Shear bond strength was tested by Instron universal testing machine in shear mode until bond failure and recorded in $\mathcal{N}$ ewtons then converted into $\mathcal{M} P$. The mean results for shear bond strengths in group $\mathcal{A}$ were 12.31 $\mathcal{M P a}$ while those for group $B$ were $10.35 \mathrm{MPa}$ and the P-value was $0.02^{\star}$. Conclusion sandblasting followed by acid etching resulted in the highest shear bond strength; while acid etching followed by sand6lasting resulted in statistically significant lower shear bond strength although it is still clinically acceptable.

1- Lecturer, Department of Orthodontics, Faculty of Dentistry, Ain Shams University, Cairo, Egypt.

2- Lecturer and Course director, Department of Orthodontics, Faculty Dentistry, Pharos University, Alexandria, Egypt. 
Egyptian

Orthodontic Journal

\section{INTRODUCTION}

Technological advances and research-based findings in the field of dentistry have constantly led to the development of new materials and techniques that are aimed at simplifying the clinical procedures among these procedures are the bonding systems. The most popular bonding systems in restorative dentistry are based on resin composite materials that are attached to the enamel surface according to a micromechanical retention principle ${ }^{1}$.

The foundation for adhesive restoratives was laid down in 1955, when Buonocore proposed that acid could be used to alter the surface of enamel to render it more receptive to bonding systems ${ }^{2}$. The primary effect of etching is to increase the surface area, and thereby change the surface from a low energy hydrophobic surface to a high energy hydrophilic surface ${ }^{3}$. To achieve this, a relatively strong acid (generally $35 \%$ to $40 \%$ phosphoric acid) is used for approximately 30 seconds to clean the surface and dissolve the minerals ${ }^{4}$.

In Orthodontics, in particular, Newman (1965) was the first author to test the bonding of plastic attachments (polycarbonate brackets) to the buccal surfaces of the teeth and to divulge such a technique ${ }^{5}$. This discovery had a great impact on Orthodontics and bonding substituted banding accordingly. Therefore resulting in significant treatment improvements including: more esthetic and hygienic appliances, elimination of posttreatment band spaces, easier caries detection and treatment, less soft tissue irritation, and decreased possibility of enamel decalcification ${ }^{5,6}$.

Acid pretreatment of the enamel surface is clinically effective and reliable. However, there are several drawbacks associated with the bonding technique, namely, toxicity of acid to oral soft tissues and time required to obtain the desired dissolution ${ }^{1}$. A further disadvantage is the difficulty in confining the etchant to the area covered by the bracket base $^{7}$. In an effort to overcome the potential risk of decalcification which this poses, several studies have investigated the effects of reduced etching times or etchant concentrations on bracket bond strengths and failure rates ${ }^{8,9}$. 
Acid etching has also been reported to cause an enamel loss ranging from 3 to 10 micro $^{10}$. Diedrich concluded from his study that $10 \%$ of enamel is lost due to acid etching, bracket removal, and clean up after debonding. He believed that an orthodontic adhesive that can eliminate the need for acid etching might be desirable in the future ${ }^{11}$.

Many investigators have been interested in the effects of sandblasting. Zachrisson found that sandblasting improves the retention and increases the bond strength when bonding to gold, porcelain, and amalgam $^{12,13}$. He also believed that sandblasting lower lingual retainer wires before bonding increases their bond strength. Several authors have independently found that sandblasting bracket bases greatly increases their retentive surface ${ }^{13}$.

Air-abrasion technology uses a high-speed stream of aluminum oxide particles propelled by air pressure. Air abrasion is based on the law of kinetic energy, which states the harder the substance, the faster the cutting speed ${ }^{14,15}$. and the softer the substance, the slower the cutting speed. Hence, enamel cuts much faster than dentin or amalgam. Air abrasion, thus has minimal effect on oral soft tissues with typical tooth surface preparation times ranging from 0.5 to 5 seconds without the additional step of rinsing ${ }^{14,15,16}$. Current clinical applications include pit and fissure sealants, composite and laminate repairs, inlay, onlay and other indirect surface preparation before bonding, and prophylaxis ${ }^{15,16}$.

This led to the successful use of sandblasting in orthodontics for both preparing teeth before bonding and for increasing bond strength. Surface roughening of enamel is a highly complex phenomenon. Many factors need to be considered including the particle size, shape and hardness of the abrasive, velocity, the microstructure of the surface being abraded and the sensitivity of the technique ${ }^{17}$. Therefore, the aim of this study was to compare the effect of sandblasting of enamel before and after conventional acid-etch bond technique on the shear bond strength.

\section{MATERIALS \& METHODS}

Sixty freshly extracted human permanent premolars (maxillary and mandibular; first and second) for orthodontic treatment purposes at the 
orthodontic department of Ain Shams University were collected and stored in normal saline at room temperature within two weeks from their extraction. The premolars were selected according to the following: inclusion criteria involved intact buccal enamel, while the exclusion criteria involved developmental abnormalities, caries, decalcification, fluorosis, surface irregularities, cracks as a result of the extraction forceps, previous bracket bonding procedures, and pretreatment chemical agents such as hydrogen peroxide. During handling of the premolars appropriate infection control procedures were employed. The teeth were cleaned from any soft tissue debris or blood and then pumiced with a rubber prophylactic cup for 30 seconds, rinsed with water spray for 5 seconds, and air-dried. The eighty premolars were then divided randomly and equally into two groups (A and B) of 30 each.

The premolars were mounted vertically by immersing their roots into blocks of self-curing acrylic (Coe Tray Plastic, GC America Inc.) in an acrylic block (10 x $10 \times 20 \mathrm{~mm}$ height) up to the cementoenamel junction to allow for standardized and secure placement during testing. The buccal surface was aligned perpendicular to the bottom of the acrylic mold this was insured via the aid of a dental surveyor (SMS surveyor, SS-36). In order to aid retention of the premolar in its mounting each root was grooved using a high-speed bur. Possible dehydration of the premolars during the curing of the resin was minimized by immersing them in distilled water at room temperature until the resin underwent complete curing, then left immersed and refrigerated to await bonding.

In Group. A, the bonding procedures involved sandblasting followed by acid etching, while in Group B the bonding procedures involved acid etching followed by sandblasting.

The pre-surface treatment for both groups was as follow, the buccal enamel surface was polished for 10 seconds with rubber cup and oil/fluoride free pumice, followed by rinsing with distilled water for 10 seconds and drying with oil-free compressed air for 10 seconds.

Sandblasting was performed utilizing 27 micron particles of aluminum oxide at 80 psi applied at a distance of $5 \mathrm{~mm}$ from the buccal tooth surface with a 0.019 -inch nozzle opening at almost $60^{\circ}$. to the 
surface (Prep Start device, Danville Materials, San Ramon, CA, USA) for 5 seconds. The application of the aluminum oxide jet was accomplished inside a closed transparent acrylic box to avoid particle aspiration by the operator. The premolars were then rinsed with water spray for 30 seconds and dried with an oil-free air source for 20 seconds. In order to obtain a standardized sandblasted area the enamel surfaces were covered in tin foil with a window-opening equal to the surface area of the bracket base.

Acid Etching was performed with $37 \%$ phosphoric acid gel (3M/Unitek) for 15 seconds, washed with air/water spray for 20 seconds, and dried with compressed oil-free air thoroughly for 20 seconds until the enamel surface gave a chalky white appearance.

A no-mix chemically cured adhesive (Rely-a-Bond, Reliance Orthodontic Products Inc. Illinois USA) was used for bracket bonding in this study. The brackets used in this study were 0.022 inch slot stainless steel premolar PEA Roth brackets (Gemini series, 3M Unitek) with a base surface area of $9.806 \mathrm{~mm}^{2}$. Bracket placement was performed at room temperature. On the prepared enamel surface, a thin coating of the primer (Rely-a-Bond, Reliance Orthodontic Products) was applied with a brush. A no-mix chemically cured orthodontic adhesive (Rely-a-Bond, Reliance Orthodontic Products, Inc., Illinois, USA) was placed on the bracket base. Each bracket was positioned on the mid coronal point of the tooth. To avoid the entrapment of air within the adhesive and to minimize the adhesive thickness the bracket was pushed in a figure print fashion with sufficient pressure to express out the excess adhesive. Attention was paid to ensure that adhesive extruded from the entire bracket base perimeter, thereby confirming the entire bonding surface was covered with adhesive. Care was taken to remove the excess adhesive with a probe around the bonded brackets, the specimens were then allowed to bench cure for 10 minutes.

The same operator performed the bonding for all the brackets. After bonding, all the samples were stored in distilled water at room temperature for $48 \mathrm{hrs}$ before testing them for shear bond strength.

The specimens were removed from the distilled water, dried, and immediately mounted on the testing machine. Shear bond strength tests 
were performed using an Instron Universal Testing Machine (Instron 8874 Corp., Canton,MA). The acrylic block sample was positioned so that the buccal surface of the tooth and the bracket base were parallel to the direction of the applied force (Figure 1a). The force was applied by means of a beveled loading stainless steel blade placed on the occlusal edge of the bracket. The specimens were stressed in an occlusogingival direction with a crosshead speed of $1 \mathrm{~mm} / \mathrm{min}$ and the shear force at bond failure was recorded (Figure $1 \mathrm{~b}$ ). The maximum force necessary to debond or initiate bracket fracture was recorded in Newton's and then converted into Mega Pascal's (MPa) by dividing the maximum load (in Newton's) by the base area of the bracket $\left(9.806 \mathrm{~mm}^{2}\right)$. Bond failure occurred at the resin/tooth interface as viewed by the naked eye for most of the samples in both groups.

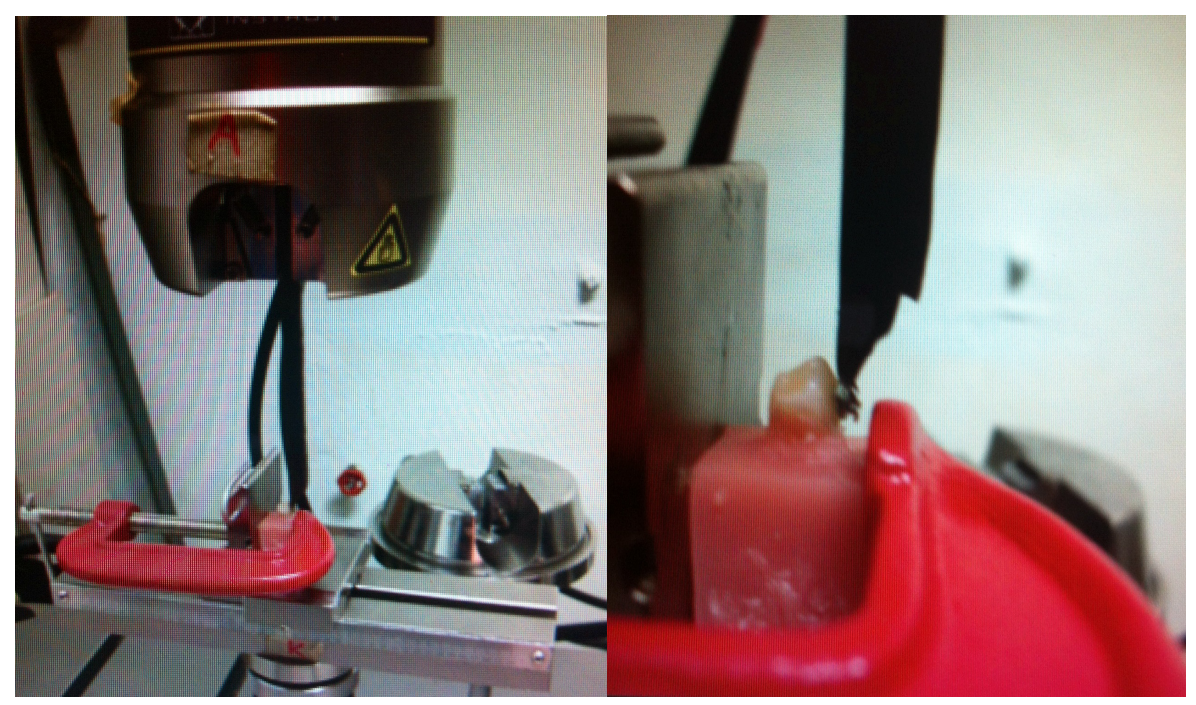

(a)

(b)

Figure 1. (a) Instron Universal Testing Machine (Instron 8874 Corp., Canton, MA). (b) Acrylic block sample secured so that the buccal surface of the tooth and the bracket base are parallel to the direction of the applied force, direction of loading in an occlusogingival direction with a crosshead. 
Egyptian

Orthodontic Journal

\section{STATISTICAL ANALYSIS}

All the measurements were introduced into an excel spreadsheet and analyzed using a standard statistical software package (SPSS version 15.0, Chicago Ill) for Windows. Descriptive statistics including the number, mean and standard deviation values for each of the two groups (A\&B) were calculated. The Independent Samples T-test was used to determine if a significant difference was present in shear bond strength between the two groups (A\&B). The level of statistical significance was set at $5 \%(\mathrm{P}$-value $\leq 0.05)$.

\section{RESULTS}

Table I: shows the Mean and Standard deviation for Sandblasting/acid etching (group A) and Acid etching/sandblasting (group B) where the mean values for group A was $12.31 \mathrm{MPa}$, whereas the mean values for group $\mathrm{B}$ were $10.35 \mathrm{MPa}$ with a difference of $1.96 \mathrm{MPa}$ between group A and group B. The Standard deviation values for group A was 3.84, whereas the standard deviation values for group B was 3.57 (Table I).

Figure 2: represents the difference in Mega Pascals for the Shear bond strength means between the two surface treatment bonding protocols in group A and group B, Sandblasting with 27 micron particles of aluminum oxide followed by acid etching with $37 \%$ phosphoric acid gel and vice versa.

The results of Independent Samples T-test (Table II) indicated that there was a significant difference $(\mathrm{P}-$ value $=0.02)$ between the bonding protocols when using Sandblasting and then Acid etching $(\mathrm{x}=12.31 \pm 3.84 \mathrm{MPa})$ (group A) as compared with that obtained when using Acid etching and then Sandblasting $(\mathrm{x}=10.3479 \pm 3.57 \mathrm{MPa})$ (group B).

Table I: Descriptive statistics including Number, Mean and Standard deviation for both the Sandblasting/acid etching group (A) and the Acid etching/sandblasting group (B).

\begin{tabular}{|l|l|c|c|c|}
\hline & \multicolumn{1}{|c|}{ Groups } & N & Mean & Std. Deviation \\
\hline \multirow{3}{*}{ Shear Bond Strength } & $\begin{array}{l}\text { Sandblasting + acid etching } \\
\text { (Group A) }\end{array}$ & 30 & 12.31 & 3.84 \\
\cline { 2 - 5 } & $\begin{array}{l}\text { Acid etching + Sandblasting } \\
\text { (Group B) }\end{array}$ & 30 & 10.35 & 3.57 \\
\hline
\end{tabular}

Volume 45 - June 2014 


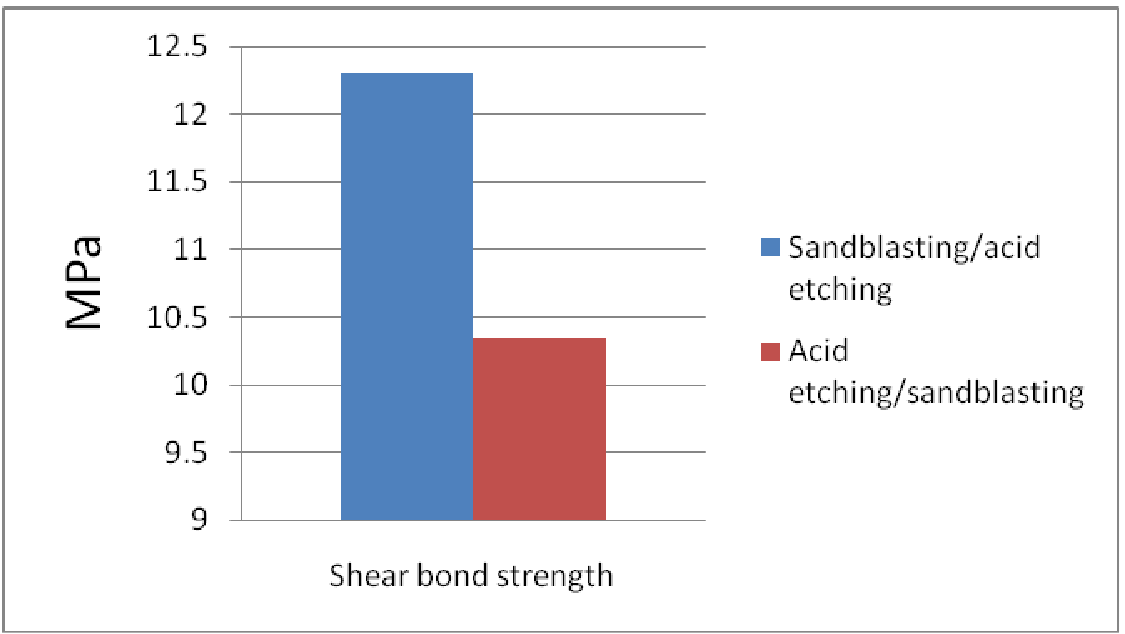

Figure 2: Graph displaying the difference between the Means for the shear bond strength of both groups Group A Sandblasting /Acid etching and Group B Acid etching /Sandblasting.

Table II: Results of the Independent Samples T-test comparing the shear bond strength in Mega Pascal's for both the Sandblasting /acid etching group (A) and the Acid etching /sandblasting group (B).

\begin{tabular}{|l|c|c|c|}
\hline \multicolumn{1}{|c|}{ Measurements } & $\begin{array}{c}\text { Sandblasting/ } \\
\text { Acid etching }\end{array}$ & $\begin{array}{c}\text { Acid etching/ } \\
\text { Sandblasting }\end{array}$ & P-value \\
\hline Shear Bond strength & $12.31 \pm 3.84$ & $10.35 \pm 3.57$ & $0.02 *$ \\
\hline
\end{tabular}

*: Significant at $\mathrm{P} \leq 0.05$

\section{DISCUSSION}

In restorative dentistry, adhesive materials are generally bonded to teeth permanently. In orthodontics, attachments are bonded for a limited time. The requirements of sufficient bond strength, ease of debonding and limited risk of permanent damage to the enamel surface are thus critical in orthodontics. Therefore bracket bonding must be simple, quick, reliable, and reversible.

In Orthodontics, the acid etching technique which is a form of micro etching was introduced by Buonocore in $1955^{2}$ this fostered the 
Egyptian

Orthodontic Journal

development of orthodontic brackets and their clinical attachment to the enamel surface directly using adhesive restorative composite, which led to the elimination of orthodontic bands and simplified the clinical steps. Bonding of brackets to enamel surface using composites is currently a well accepted and a well established procedure in Orthodontics and the efficacy of this technique has been widely documented in the literature ${ }^{1,3,7,9,10}$. Therefore, etching of enamel surfaces with $35-40 \%$ phosphoric acid has continued to be the standard by which all other enamel surface preparation techniques are measured.

Yet there is wide agreement in the literature that acid etching causes iatrogenic damage to the enamel ${ }^{8,11}$. Enamel loss and the appearance of cracks from acid etching have been described. On average. these cracks reach a depth of $80 \mu \mathrm{m}^{11}$. The resin probably remains in the enamel after debonding, and this could affect plaque retention, susceptibility to caries and discoloration ${ }^{18}$.

Many techniques are currently advocated and used for bonding. Among these techniques is air-abrasion, which is regarded as a form of macroetching. Recently, air-abrasion technology has been examined for potential applications within the field of orthodontics. especially as an alternate method of enamel surface treatment. Air-abrasion technology uses a high-speed stream of aluminum oxide particles propelled by air pressure. The recent introduction of intraoral sandblasters has provided a break-through in revolutionizing the air-abrasion technology.

According to Olsen et $\mathrm{al}^{1}$, sandblasting with aluminum oxide results in an irreversible loss of enamel, whereas acid etching shows intact organic components that allow the etched enamel surface to be remineralized. However, Reisner et $\mathrm{al}^{19}$ reported that the enamel loss resulting from air-abrasion (sandblasting) at low pressure and a short exposure time is smaller than in case of acid etching with $37 \%$ phosphoric acid. It is also possible that the removal of inorganic and organic components of the enamel matrix by means of the sandblasting technique prevents resin attachment to the enamel after debonding. It is well documented that the bond strength of sandblasting alone as a prebonding procedure has the lowest bond strength as stated by Olsen et. $\mathrm{al}^{1}$ and Reisner et. $\mathrm{al}^{19}$ thus it could not be used as an alternative to acid etching. 
Egyptian

Orthodontic Journal

Therefore, attempts were made on the combination of sandblasting followed by acid etching, which proved to have the highest bond strength when compared to acid etching alone ranging between 12 to $13 \mathrm{MPa}^{19}$. The results in this study for sandblasting followed by acid etching were 12.31 MPa which are consistent with Borsatto et. $\mathrm{al}^{20}$. Whereas the shear bond strength for acid etching followed by sandblasting decreased significantly to $10.35 \mathrm{MPa}$ (P-value $0.02 *$ ). This decrease in shear bond strength, although it is still clinically acceptable according to Reynolds ${ }^{3}$, may be attributed to two reasons. First that sandblasting resulted in removal of both the organic and inorganic content of the enamel and second that the particles of aluminum oxide from the sandblasting and the removed enamel particles blocked the micro pores thus decreasing the depth of the micro pores created by the acid etching and thereby decreasing shear bond strength.

\section{CONCLUSION}

- Sandblasting followed by acid etching results in the highest shear bond strength.

- Reversing the protocol to acid etching followed by sandblasting results in significant decrease in shear bond strength.

\section{REFERENCES}

1. Olsen ME, Bishara SE, Jakobsen JR. Comparison of shear bond strength and surface structure between conventional acid etching and air abrasion of human enamel. Am J Orthod Dentofac Orthop 1997;112:502-6.

2. Buonocore $\mathrm{MG}, \mathrm{A}$ simple method of increasing the adhesion of acrylic filling materials to enamel surfaces. J Dent Res 1995;34:49-53.

3. Reynolds IR. A review of direct orthodontic bonding. Br J Orthod 1975:2:171-80.

4. Wang WN, Yeh CL, Fang BD, Sun KT, Arvystas MG. Effect of H3PO4 concentration on bond strength. Angle Orthod 1994;64:377-82. 
5. Newman GV. Epoxy adhesives for orthodontic attachments: progress report. Am J Orthod 1965;51:901-12.

6. Zachrisson B. Cause and prevention of injuries to teeth and supporting structures during orthodontic treatment. Am J Orthod 1976;69:285-300.

7. Sargison AE, Mccabe JF, Millett DT. A laboratory investigation to compare enamel preparation by sandblasting or acid etching prior to bracket bonding. Br J Orthod 1999;26:141-46.

8. Barkmeier WW, Gwinnett SJ, Shaffer SE. Effects of enamel etching time on bond strength and morphology. J Clin Orhtod 1985;16:36-37.

9. Legier BS, Retief DH, Bradley EL. Effects of phosphoric acid concentration and etching duration on enamel depth of etch:an invitro study. Am J Orhtod 1990;98:154-60.

10. Levitt HL, Zachrisson BU. Orthodontic bonding. In: Marks MH, Corn H. editors. Atlas of adult orthodontics: functional and esthetic enhancement. Philadelphia: Lea \& Febiger, 1989:506-11.

11. Diedrich P. Enamel alterations from bracket bonding and debonding. Am J Orthod 1981;79:500-22.

12. Zachrisson BU. Buyukyilmaz T. Recent advances in bonding to gold, amalgam, and porcelain. J Clin Orthod 1993:27:661-75.

13. Millett D, McCabe JF, Gordon PH. The role of sandblasting on the retention of metallic brackets applied with glass ionomer cement. $\mathrm{Br}$ J Orthod 1993;20: 117-22.

14. Goldstein R, Parkins F. Air-abrasive technology: its new role in restorative dentistry. JADA 1994;125:551-7.

15. Gerbo L, Barnes C, Leinfelder K. Applications of the air-powder polisher in clinical orthodontics. Am J Orthod Dentofac Orthop 1993;103:71-3.

16. Wolf D, Powers J, O'Keefe K. Bond strength of composite to etched and sandblasted porcelain. Am J Dent 1993;6:155-8. 
17. White SN. Yu X. High-energy abrasion: an innovative esthetic modality to enhance adhesion. J Esthetic Dent 1994;6:267-73.

18. Van Waveren Hogervorst WL, Feilzer AJ, Prahl-Andersen B. The air-abrasion technique versus the conventional acid-etching technique: A quantification of surface enamel loss and a comparison of shear bond strength. Am J Orthod Dentofacial Orthop, 2000;117:20-26.

19. Reisner KR, Levitt HL, Mante F. Enamel preparation for orthodontic bonding: A comparison between the use of a sandblaster and current techniques. Am J Orthod Dentofac Orhtop 1997;111:366-73.

20. Borsatto MC, Catirse AB, Palma DR, Corona SA. Shear bond strength of enamel surface treated with air-abrasion system. Braz Dent J 2002;13(3):175-78. 